\title{
Enterprise Risk Management in Construction Companies: Recent Trend Xianbo Zhao*
}

School of Engineering and Technology, Central Queensland University, Australia

*Corresponding Author: Xianbo Zhao, School of Engineering and Technology, Central Queensland University, Australia, E-mail: b.zhao@cqu.edu.au

Received date: August 29, 2016; Accepted date: August 30, 2016; Published date: September 15, 2016

Citation: Zhao X (2016) Enterprise Risk Management in Construction Companies: Recent Trend. J Steel Struct Constr 2: e107. doi: 10.4172/2472-0437.1000e107

Copyright: () 2016 Zhao X. This is an open-access article distributed under the terms of the Creative Commons Attribution License, which permits unrestricted use, distribution, and reproduction in any medium, provided the original author and source are credited.

\section{Editorial}

Traditionally, risk management is segmented and conducted in separate business units or departments (i.e. silos) within a company. Under silo-based risk management, silos deal with their own risks, and none single group or person in the company has a grasp of the entire exposure that the company faces. This is attributed to the way people think about solving problems, the existing organizational structure, and the evolution of risk management practice. In addition, this is due to the fact that each silo within a company possesses the best expertise to address the risks within its area of responsibility.

In recent years, a paradigm shift has occurred in the way companies view risk management, and the trend has moved towards a holistic view of risk management. As the fundamental paradigm in this trend, enterprise risk management (ERM) has attracted much worldwide attention. The Committee of Sponsoring Organizations of the Treadway Commission (COSO) defined ERM as "a process, effected by an entity's board of directors, management and other personnel, applied in strategy setting and across the enterprise, designed to identify potential events that may affect the entity, and manage risk to be within its risk appetite, to provide reasonable assurance regarding the achievement of entity objectives". ERM agrees with the modern portfolio theory, which states that it is possible to build a portfolio that is reasonably safe even though it contains a number of uncorrelated or negatively correlated high-risk investments.

To follow the recent trend of risk management, the construction firms venturing into overseas markets are recommended to hold a global view to identify systemic risks rather than just project-only risks. Some professional reports have forecast ERM to grow in the construction industry. Compared with the traditional approach, ERM enables companies to shift the focus of the risk management function from primarily defensive to increasingly offensive and strategic and provides a new way to improve PRM in construction firms. Given the complexity and diversity of the risks, construction firms have been seen as prime candidates for ERM adoption.

In recent years, there have been some studies focused on ERM in construction operations. Specifically, a definition of ERM maturity has been proposed and an ERM maturity model was developed to assess the sophistication of ERM implementation in construction companies; the factors driving and hindering ERM implementation, as well as the critical success factors of ERM have been also identified and analyzed in tandem with several theories of organizational behavior; the effect of company characteristics on ERM implementation in construction companies has been analyzed as well; and finally, a computerized knowledge-based decision support system (KBDSS) was developed to facilitate ERM implementation in construction companies.

Some areas of ERM are also worth of research. Firstly, because potential benefits significantly drove ERM implementation, the management staff should be convinced that these benefits can outweigh the cost related to ERM implementation. Future research would develop a set of metrics that can measure ERM performance, which could demonstrate the tangible ERM benefits to the management staff. Secondly, future research can examine the impact of implementing ERM on project performance, and the differences in project performance between construction companies with different ERM maturity levels. As construction companies are project-based, the positive impact on project performance can be a tangible benefit of ERM. If the improvement in project performance from implementing ERM could be confirmed, more construction companies would be motivated to implement ERM. In addition, future research would investigate the appropriate organizational learning styles, motivation measures, and leadership styles for ERM implementation in construction companies. Lastly, further research would develop a benchmarking system for ERM and establish a database containing the maturity scores collected from a large number of construction companies with different characteristics. The benchmarking system could be embedded into the KBDSS, which allows the users to compare their ERM implementation with the average implementation level of all the companies and those with certain characteristics, respectively. Such an updated KBDSS therefore allows the users to make better informed decisions relating to ERM. 